\title{
Síndrome de Burnout entre enfermeiros de um hospital geral da cidade do Recife
}

\author{
BURNOUT SYNDROME AMONG GENERAL HOSPITAL NURSES IN RECIFE \\ SÍNDROME DE BURNOUT ENTRE ENFERMEROS DE UN HOSPITAL GENERAL DE LA \\ CIUDAD DE RECIFE
}

\section{Renata Hirschle Galindo', Katia Virginia de Oliveira Feliciano ${ }^{2}$, Raitza Araújo dos Santos Lima ${ }^{3}$, Ariani Impieri de Souza ${ }^{4}$}

\section{RESUMO}

Este estudo descritivo, transversal, censitário, identificou Burnout e alguns fatores associados entre enfermeiros da assistência pediátrica e tocoginecológica de hospital geral do nível terciário de atenção do Recife (PE). Participaram 63 profissionais $(98,4 \%$ do total) que responderam a um questionário auto-aplicável (aspectos sócio-demográficos, condições laborais e Maslach Burnout Inventory). Na análise utilizou-se qui-quadrado, com nível de confiança de $95 \%$. Predominou o gênero feminino $(92,1 \%)$, com até cinco anos de profissão (68,2\%), sendo $52,5 \%$ da área pediátrica. Constataram-se altos níveis de exaustão emocional $(49,2 \%)$ e despersonalização $(27,0 \%)$ e baixo nível de realização profissional $(4,8 \%)$, estando $4,7 \%$ com Burnout. Mostraram associação: alto nível de exaustão emocional e realizar frequentemente/sempre tarefas com muita rapidez $(p=0,039)$ e receber salário incompatível com o esforço empregado $(p=0,016)$; altos níveis de despersonalização e ter até cinco anos de profissão $(p=0,010)$ e efetuar frequentemente/sempre tarefas com muita rapidez $(p=0,009)$. Para $19,0 \%$ pelo menos duas das três dimensões apontavam alta propensão à síndrome.

\section{DESCRITORES}

Esgotamento profissional

Enfermagem

Enfermagem pediátrica

Saúde do trabalhador

\begin{abstract}
This descriptive, cross sectional, census study identified the occurrence of Burnout and some associated factors among nurses working in obstetrics \& gynecology and pediatric care at a general tertiary hospital in Recife. Sixty-three nurses (98.4\%) answered a self-administered questionnaire (sociodemographic aspects, working conditions, and Maslach Burnout Inventory). Chi-square was used in the analysis with a $95 \%$ confidence level. Most participants were female $(92.1 \%)$, with up to five years in the career $(68.2 \%), 52.5 \%$ in pediatric area. High levels of emotional stress $(49.2 \%)$ and depersonalization (27.0\%) were identified, as well as low professional fulfillment $(4.8 \%)$, and $4.7 \%$ presented Burnout. The following factors wee associated: high levels of emotional stress and often/always perform tasks very quickly $(p=0.039)$ and receiving a salary incompatible to the effort employed ( $p=0.016)$; high levels of depersonalization and with up to five years in this career $(p=0.010)$ and often/always perform tasks very quickly $(p=0.009)$. For $19.0 \%$, at least two of the three dimensions pointed to high propensity to the syndrome.
\end{abstract}

\section{DESCRIPTORS \\ Burnout, professional \\ Nursing \\ Pediatric nursing \\ Occupational health}

\section{RESUMEN}

Estudio descriptivo, transversal, censitario, identificó Burnout y factores asociados entre enfermeros de atención pediátrica y tocoginecología de hospital general de nivel terciario de atención en Recife-PE. Participaron 63 profesionales $(98,4 \%$ del total), que respondieron cuestionario autoaplicable (aspectos sociodemográficos, condiciones laborales y Maslach Burnout Inventary). Analizado según Qui-cuadrado, nivel de confianza 95\%. Predominó sexo femenino $(92,1 \%)$, con hasta cinco años de profesión $(68,2 \%)$, perteneciendo $52,5 \%$ al área pediátrica. Se constataron altos niveles de agotamiento emocional $(49,2 \%)$ y despersonalización (27,0\%), y bajo nivel de realización profesional $(4,8 \%)$, sufriendo $4,7 \%$ de Burnout. Mostraron asociación: altos niveles de agotamiento emocional, realizar frecuentemente/siempre tareas con mucha rapidez $(p=0,039)$, recibir salario incompatible con esfuerzo $(p=0,016)$; alto nivel de despersonalización y tener hasta cinco años de profesión $(p=0,010)$ y efectuar frecuentemente/siempre tareas con mucha rapidez $(p=0,009)$. Para $19,0 \%$ al menos dos de las tres dimensiones marcaban alta propensión al síndrome.

\section{DESCRIPTORES \\ Agotamiento profesional \\ Enfermería \\ Enfermería pediátrica \\ Salud laboral}

\footnotetext{
${ }^{1}$ Graduanda de Medicina da Faculdade Pernambucana de Saúde. Bolsista PIBIC/CNPq/IMIP. Recife, PE, Brasil. renatahirschle@hotmail.com. ${ }^{2}$ Médica. Doutora em Medicina Preventiva pela Universidade de São Paulo. Professora do Programa de Pós-Graduação em Saúde Materno-Infantil do Instituto de Medicina Integral Professor Fernando Figueira. Recife, PE, Brasil. kvofeliciano@gmail.com. ${ }^{3}$ Graduanda de Medicina da Faculdade Pernambucana de Saúde. Bolsista PIBIC/CNPq/IMIP. Garanhuns, PE, Brasil. raitza05@yahoo.com.br ${ }^{4}$ Médica. Doutora em Nutrição da Universidade Federal de Pernambuco. Professora do Programa de Pós-Graduação em Saúde Materno-Infantil do Instituto de Medicina Integral Professor Fernando Figueira. Recife, PE, Brasil. arianii@terra.com.br
} 


\section{INTRODUÇÃO}

As transformações sociais, econômicas, jurídicas, organizacionais e técnicas do trabalho em saúde exercem profunda influência sobre o processo de saúde-adoecimento e a qualidade de vida nos contextos laborais ${ }^{(1)}$. Observa-se, no Mundo, tendência crescente para abordar os aspectos negativos da experiência no trabalho, utilizando a perspectiva do Burnout ${ }^{(1-3)}$. 0 conceito de referência ainda é o de Christina Maslach e Susan Jackson: a síndrome resulta de um processo sequencial que envolve três dimensões: (a) exaustão emocional: desgaste ou perda dos recursos emocionais que leva à falta de entusiasmo, frustração e tensão; (b) despersonalização: desenvolvimento de sentimentos e atitudes negativas no trabalho; (c) diminuição da realização pessoal no trabalho: tendência à auto-avaliação profissional negativa, tornando-se infeliz e insatisfeito, o que origina sentimentos de inadequação e fracasso(1).

Os modelos explicativos do burnout tornaram-se gradualmente mais complexos, abrangendo condicionantes individuais, organizacionais do trabalho e sociais. Estudos internacionais $^{(1-2,4)}$ e nacionais ${ }^{(3,5-6)}$ constatam que, apesar da multidimensionalidade, essa síndrome mantém uma relação estreita com a percepção de suporte organizacional, demonstrando a importância do papel mediador da instituição para a saúde e o bemestar no trabalho. Desse modo, o Burnout é considerado como uma resposta ao estresse laboral percebido que surge quando as estratégias utilizadas pelos profissionais para enfrentar o estresse mostram-se ineficazes, apontando a organização como variável mediadora entre o estresse percebido e suas consequências $^{(1)}$. Na prevenção da síndrome é preciso dar ênfase às transformações requeridas pelos aspectos situacionais próprios dos contextos de trabalho(7-8).

Embora o burnout acometa as mais diversas profissões, aquelas em que se lida com o sofrimento alheio aumentam a vulnerabilidade ${ }^{(4-5,7-8)}$. Os enfermeiros estão submetidos continuamente a elementos geradores do estresse laboral, que são associados à síndrome: a escassez de pessoal, que supõe acúmulo de tarefas e sobrecarga laboral, o trabalho por turno e/ou noturno, o trato com usuários problemáticos, o conflito e ambiguidade de papéis, a baixa participação nas decisões, a inexistência de plano de cargos e salários, o sentimento de injustiça nas relações laborais e os conflitos com colegas e/ou instituição. Além disso, as contínuas interrupções e reorganização das tarefas, que agravam a sobrecarga, o lidar de modo muito próximo com a morte, a criação de vínculo afetivo com o paciente e seu sofrimento, a exposição constante a risco de conta- minação e violência. A frágil organização política dessa categoria profissional e o desconhecimento do papel do enfermeiro numa organização hospitalar potencializam a vulnerabilidade ${ }^{(4,8-13)}$.

Apesar do reconhecimento de que a enfermagem é uma das profissões mais estressantes, existem controvérsias no que diz respeito à relação entre o estresse laboral e os níveis esperados de burnout entre enfermeiros $^{(4)}$. Pesquisas que utilizam os mesmos critérios para identificar a síndrome têm mostrado, de um lado, a importante distribuição mundial do burnout nessa categoria profissional, com os enfermeiros apresentando os níveis maiores de exaustão e despersonalização, o que enfatiza a sua maior propensão ao desenvolvimento da síndrome ${ }^{(10-11,14)}$. De outro, uma baixa ocorrência do burnout, propiciando questionamentos sobre as razões que justificariam esta disparidade entre o que é observado e o que é esperado e relatado na literatura quanto à magnitude do distúrbio em enfermeiros ${ }^{(4,13,15)}$. No Brasil, encontra-se ampla variação nos valores de burnout identificados nos poucos estudos envolvendo enfermeiros e auxiliares de enfermagem que atuam no âmbito da assistência hospitalar ${ }^{(9-10,13,15)}$.

Após revisão da produção científica, encontra-se baixa ocorrência de burnout e alto nível de estresse laboral entre enfermeiros satisfeitos com o seu trabaIho(4). A satisfação estava associada ao suporte informacional, ao suporte social no trabalho, à oportunidade de aprendizagem e progressão e à participação nas decisões. Também identifica elementos sugestivos de que frequências menores do que as esperadas estão relacionadas com a habilidade para administrar as situações estressoras do cotidiano, que é denominada de coping ${ }^{(16)}$, tornando mais lento o avanço do processo sequencial que culmina no burnout. As habilidades para lidar com as demandas internas e externas advindas do estresse laboral pode visar o controle (estratégias voltadas ao problema) ou o escape (voltadas à emoção: negação da situação, distanciamento, atenção seletiva). O coping de escape está associado com uma maior frequência de exaustão emocional(6,17).

O burnout tem consequências sobre a saúde física e mental, entre elas as alterações cardiovasculares, fadiga crônica, cefaléias, enxaqueca, úlcera péptica, insônia, dores musculares ou articulares, ansiedade, depressão, irritabilidade, entre outras. Também pode interferir na vida doméstica, com as relações familiares ressentindo-se da falta de tempo para o cuidado dos filhos e o lazer. O contexto do trabalho é afetado pelo absenteísmo, rotatividade de emprego, aumento de condutas violentas e diminuição da qualidade do 
trabalho ${ }^{(3,8-9)}$. Com este estudo, pretende-se contribuir para a busca de formas efetivas de lidar com a promoção da saúde no trabalho e a prevenção do burnout, ações de grande importância para a qualidade de vida laboral dos enfermeiros e a qualidade da assistência fornecida por esses profissionais ${ }^{(2,6,8)}$.

\section{OBJETIVO}

Identificar a ocorrência de burnout, detalhando as três dimensões da síndrome, e alguns fatores sócio-demográficos e das condições do trabalho que lhes são associados entre enfermeiros de hospital geral do nível terciário de atenção, da cidade do Recife.

\section{MÉTODO}

Foi realizado um estudo descritivo, de corte transversal, censitário, de outubro a novembro de 2009, em hospital geral do nível terciário de atenção do Sistema Único de Saúde, na cidade do Recife, o qual é referência estadual e da região Nordeste para atenção à mulher e à criança. A partir da listagem fornecida pelo serviço de saúde, devidamente atualizada mediante contato com os setores envolvidos, todos os 64 enfermeiros que pertenciam ao quadro funcional e prestavam assistência no ambulatório, enfermaria e urgência-emergência do setor de Pediatria e Tocoginecologia foram contatados. Após serem informados sobre a pesquisa e assinarem o termo de consentimento livre e esclarecido, receberam o questionário auto-aplicável e anônimo, tendo agendado com a pesquisadora de campo a data da devolução. Destes, 63 (98,4\% do total) devolveram o questionário. Um profissional que deixou de ser funcionário do serviço não foi localizado.

O questionário constava de duas partes: (1) aspectos sócio-demográficos, formação profissional e condições de trabalho; (2) Maslach Burnout Inventory - MBI, constituído por escala Likert com 22 questões sobre as três dimensões da síndrome: nove avaliam a exaustão emocional, cinco a despersonalização e oito a realização profissional. A cada uma das questões do MBI foram atribuídos graus de intensidade crescente: 1 (nunca), 2 (algumas vezes por ano), 3 (uma vez por mês), 4 (algumas vezes por mês), 5 (uma vez por semana), 6 (algumas vezes por semanas) e 7 (todos os dias). Instrumento mais aplicado no mundo para avaliar o burnout, o $\mathrm{MBI}$ foi traduzido para o português e validado em 1995, obtendo um alfa de Cronbach de 0,86 na subescala de exaustão emocional, 0,69 em despersonalização e 0,76 em realização profissional(18). Efetuou-se estudo piloto para proceder aos ajustes necessários na primeira parte do questionário.

O programa Epi Info 6.04d foi utilizado para a construção do banco e a análise estatística dos dados. Em cada subescala do $\mathrm{MBI}$ os profissionais foram classificados, com base nos critérios de Maslach, para exaustão emocional: alto nível - igual ou maior do que 27; nível médio - entre 19 e 26; e nível baixo - igual ou menor do que 18. Para despersonalização: alto nível - igual ou maior do que 13; nível médio - entre sete e 12; e nível baixo - igual ou menor do que seis. Para realização pessoal: alto nível - igual ou maior do que 40; nível médio - entre 34 e 39; e nível baixo - igual ou menor do que 33. Pontuações altas em exaustão emocional e despersonalização e pontuações baixas em realização pessoal no trabalho indicam a ocorrência de burnout ${ }^{(1-2,7)}$.

Testou-se a associação entre as variáveis sócio-demográficas, da formação profissional e do trabalho e as três dimensões do burnout. Estabeleceu-se a frequência da síndrome, bem como a frequência de quem apresentou pelo menos uma ou duas das três dimensões, indicando propensão ao burnout. A existência de diferenças significativas foi avaliada usando o qui-quadrado, com um nível de significância de 5\%. O termo tendências foi utilizado para descrever resultados nos quais se delineavam diferenças com significância estatística entre 0,05 e 0,10. O projeto foi aprovado pelo Comitê de Ética em Pesquisa do Instituto de Medicina Integral Prof. Fernando Figueira - IMIP, conforme o parecer $n$ ㅇ 1480 de 08/07/2009.

\section{RESULTADOS}

Os enfermeiros estudados eram predominantemente do gênero feminino (92,1\%), tinham mediana de 29 anos de idade (intervalo interquartis de 27 a 36 anos) e $50,8 \%$ viviam em união civil estável. Aproximadamente $68,2 \%$ tinham até cinco anos de profissão (mediana de quatro anos e intervalo interquartis de dois a nove anos); 52,5\% atuavam na área pediátrica e 52,5\% eram especialistas na área de atuação. Percentual de 45,2\% estava vinculado a dois serviços e $85,7 \%$ superpunham mais de cinco atividades num mesmo serviço. Realizavam atividades na assistência hospitalar $(95,2 \%)$, burocracia $(66,7 \%)$, ensino em graduação $(47,6 \%)$, assistência ambulatorial $(23,8 \%)$, pesquisa $(23,8 \%)$ e no ensino em pós-graduação $(12,7 \%)$. Ao de redor de $71,0 \%$ trabalhavam como plantonistas.

Metade dos profissionais apresentava altos níveis de exaustão emocional, $27,0 \%$ despersonalização e $4,8 \%$ revelou baixo nível de realização pessoal no trabalho. Foi elevada a proporção daqueles com níveis médios de exaustão emocional e despersonalização. Em 68,3\% dos enfermeiros pelo menos uma das três dimensões indicava alta propensão ao burnout, enquanto para $27,0 \%$ pelo menos duas das três dimensões apontavam alta propensão à síndrome. Ao redor de $4,7 \%$ estavam acometidos de burnout (Tabela 1). 
Tabela 1- Níveis das três dimensões do Maslach Burnout Inventory e ocorrência de burnout entre enfermeiros de hospital geral do Recife, PE, Brasil - 2009

\begin{tabular}{|c|c|c|}
\hline Dimensões & $\mathbf{n}^{\mathbf{o}}$ & $\%$ \\
\hline \multicolumn{3}{|l|}{ Exaustão emocional } \\
\hline Baixo & 13 & 20,6 \\
\hline Médio & 19 & 30,2 \\
\hline Alto & 31 & 49,2 \\
\hline \multicolumn{3}{|l|}{ Despersonalização } \\
\hline Baixo & 9 & 14,3 \\
\hline Médio & 37 & 58,7 \\
\hline Alto & 17 & 27,0 \\
\hline \multicolumn{3}{|l|}{ Realização pessoal no trabalho } \\
\hline Baixo & 3 & 4,8 \\
\hline Médio & 7 & 11,1 \\
\hline Alto & 53 & 84,1 \\
\hline $\begin{array}{l}\text { Pelo menos uma das três dimensões indica } \\
\text { propensão ao burnout }\end{array}$ & 43 & 68,3 \\
\hline $\begin{array}{l}\text { Pelo menos duas das três dimensões indicam } \\
\text { propensão ao burnout }\end{array}$ & 17 & 27,0 \\
\hline Burnout & 3 & 4,7 \\
\hline
\end{tabular}

No que diz respeito às dimensões do burnout, no tocante à exaustão emocional, os enfermeiros todos os dias $(17,5 \%)$ e algumas vezes por semana $(23,8 \%)$ sentiam que estavam esgotados após o término do trabalho. Todos os dias $(12,7 \%)$ e algumas vezes por semana $(17,5 \%)$ que estavam trabalhando demais. Todos os dias $(15,4 \%)$ e algumas vezes por semana $(7,9 \%)$ que estavam no limite de suas possibilidades. Uma vez por mês sentiam que estavam trabalhando demais $(41,3 \%)$, o trabalho estava the desgastando $(38,1 \%)$, ficavam esgotados pela manhã ao pensar no trabalho $(33,3 \%)$ e esgotados após finalizá-lo $(31,7 \%)$. Algumas vezes por ano sentiam-se decepcionados com o seu trabalho $(39,7 \%)$, cansados por trabalhar todos os dias com pessoas $(38,1 \%)$, frustrados com o trabalho $(38,1 \%)$ e no limite das suas possibilidades $(34,9 \%)$.

Quanto à despersonalização, esses profissionais sentiam todos os dias $(4,8 \%)$ e algumas vezes por semana $(11,1 \%)$ que os pacientes os culpavam por seus problemas. Todos os dias $(6,3 \%)$ e algumas vezes por semana $(6,3 \%)$ que se tornaram mais duros com as pessoas. Todos os dias que estavam se enrijecendo emocionalmente $(6,3 \%)$ e algumas vezes por semana que tratavam as pessoas como objetos impessoais $(4,7 \%)$. Algumas vezes por ano $(27,0 \%)$ e uma vez por mês $(27 \%)$ sentiam que estavam mais duros com as pessoas. Algumas vezes por ano $(28,6 \%)$ e uma vez por mês $(22,2 \%)$ sentiam que estavam se enrijecendo emocionalmente. Algumas vezes por ano $(25,4 \%)$ e uma vez por mês $(20,6 \%)$ que os pacientes os culpavam por seus problemas. Nunca deixaram de se importar com as pessoas que atendiam (90,5\%) e nunca tratavam as pessoas como objetos impessoais $(65,1 \%)$.

Nenhum dos enfermeiros respondeu nunca para as questões acerca da realização pessoal no trabalho. Algumas vezes por ano (14,3\%) e uma vez por mês (7,9\%) sentiam-se vigorosos no trabalho. Uma vez por mês sentiam-se estimulados após trabalhar com pessoas $(17,5 \%)$, criavam um clima agradável no trabalho $(15,9 \%)$, manejavam os problemas emocionais com calma $(15,9 \%)$ e conseguiam coisas valiosas no trabalho (14,3\%). Algumas vezes por semana sentiam-se vigorosos no trabalho $(34,9 \%)$, manejavam os problemas emocionais com calma $(28,6 \%)$, criavam um clima agradável no trabalho $(23,8 \%)$ e sentiam-se estimulados após trabalhar com pessoas $(23,8 \%)$. Todos os dias atendiam facilmente às pessoas $(77,8 \%)$, tratavam com eficiência os problemas das pessoas $(74,6 \%)$ e exerciam influência positiva na vida das pessoas $(66,7 \%)$.

Uma proporção significativamente maior dos profissionais que frequentemente/sempre realizavam suas tarefas com muita rapidez e daqueles que consideravam o salário recebido incompatível com o esforço empregado apresentou nível alto de exaustão emocional. Houve tendência para maior percentual dos profissionais do gênero feminino e que tinham até cinco anos de formados referirem exaustão emocional alta. Observou-se que ter até cinco anos de formado e realizar frequentemente/sempre suas tarefas com muita rapidez estavam associadas com alto nível de despersonalização. Existiu tendência à baixa realização pessoal no trabalho entre os enfermeiros que acumulavam funções diferentes no mesmo serviço e que não vislumbravam quaisquer possibilidades de ascensão profissional (Tabela 2).

Nenhum enfermeiro respondeu nunca quando interrogado sobre a frequência com que tinha tempo suficiente para cumprir todas as tarefas do trabalho e com que as realizava com menor rapidez. Não houve associação estatística entre as três dimensões do burnout e as variáveis: área de atuação, número de locais de trabalho, superposição de níveis de atenção, carga horária de trabalho e tempo suficiente para cumprir as tarefas.

Dos três profissionais acometidos pelo burnout todos eram mulheres: duas com até cinco anos de profissão; duas atuavam na área de tocoginecologia; duas estavam vinculadas a dois serviços de saúde; uma acumulava funções diferentes no mesmo serviço; duas às vezes tinham tempo suficiente para cumprir as tarefas; todas frequentemente/sempre realizavam suas tarefas com muita rapidez e consideravam o salário recebido incompatível com o trabalho. Constatou-se tendência ao burnout entre os enfermeiros que não tinham expectativa de ascensão profissional $(p=0,090)$. 
Tabela 2 - Níveis das três dimensões do burnout, segundo gênero, tempo de profissão, condições de trabalho e recompensas entre enfermeiros de hospital geral do Recife, PE, Brasil - 2009

\begin{tabular}{|c|c|c|c|c|c|c|c|c|c|c|c|c|}
\hline \multirow{3}{*}{ Variáveis } & \multicolumn{3}{|c|}{ Exaustão emocional } & \multicolumn{4}{|c|}{ Despersonalização } & \multicolumn{5}{|c|}{ Realização profissional } \\
\hline & Baixo & Médio & Alto & $\mathrm{P}$ & Baixo & Médio & Alto & $\mathrm{p}$ & Baixo & Médio & Alto & $\mathrm{p}$ \\
\hline & $\%$ & $\%$ & $\%$ & & $\%$ & $\%$ & $\%$ & & $\%$ & $\%$ & $\%$ & \\
\hline \multicolumn{13}{|l|}{ Gênero } \\
\hline Masculino $(\mathrm{n}=5)$ & 60,0 & 20,0 & 20,0 & 0,074 & 40,0 & 60,0 & $\ldots$ & 0,137 & $\ldots$ & $\ldots$ & 100 & 0,599 \\
\hline Feminino $(\mathrm{n}=48)$ & 17,2 & 31,0 & 51,8 & & 12,1 & 58,6 & 29,3 & & 5,2 & 12,1 & 82,7 & \\
\hline \multicolumn{13}{|l|}{ Tempo de profissão (anos) } \\
\hline $1-5(n=43)$ & 18,6 & 23,2 & 58,2 & 0,099 & 4,6 & 65,2 & 30,2 & 0,006 & 4,6 & 13,9 & 81,5 & 0,574 \\
\hline$\geq 6(\mathrm{n}=20)$ & 25,0 & 45,0 & 30,0 & & 35,0 & 45,0 & 20,0 & & 5,0 & 5,0 & 90,0 & \\
\hline Nunca/Às vezes $(n=23)$ & 34,8 & 39,1 & 26,1 & 0,015 & 30,4 & 56,6 & 13,0 & 0,009 & $\ldots$ & 8,7 & 91,3 & 0,343 \\
\hline Frequente/Sempre $(n=40)$ & 12,5 & 25,0 & 62,5 & & 5,0 & 60,0 & 35,0 & & 7,5 & 12,5 & 80,0 & \\
\hline \multicolumn{13}{|c|}{ Acumula funções diferentes no mesmo serviço } \\
\hline $\operatorname{Sim}(n=37)$ & 16,2 & 27,0 & 56,8 & 0,336 & 10,8 & 56,8 & 32,4 & 0,406 & 8,1 & 16,2 & 75,7 & 0,083 \\
\hline Não (n=26) & 26,9 & 34,6 & 38,5 & & 19,2 & 61,6 & 19,2 & & $\ldots$ & 3,9 & 96,1 & \\
\hline \multicolumn{13}{|c|}{ Compatibilidade salário /esforço empregado } \\
\hline $\operatorname{Sim}(n=4)$ & 75,0 & 25,0 & $\ldots$ & 0,016 & 25,0 & 75,0 & $\ldots$ & 0,430 & $\ldots$ & $\ldots$ & 100 & 0,668 \\
\hline Não (n=59) & 16,9 & 30,5 & 52,5 & & 13,5 & 57,7 & 28,8 & & 5,1 & 11,9 & 83,0 & \\
\hline \multicolumn{13}{|c|}{ Possibilidade de ascensão profissional } \\
\hline $\operatorname{Sim}(n=12)$ & 23,5 & 31,4 & 45,1 & 0,343 & 15,7 & 62,7 & 21,6 & 0,134 & 1,9 & 11,8 & 86,3 & 0,097 \\
\hline Não (n=51) & 8,3 & 25,0 & 66,7 & & 8,3 & 41,7 & 50,0 & & 16,7 & 8,3 & 75,0 & \\
\hline \multicolumn{13}{|c|}{ Possibilidade de ascensão profissional } \\
\hline $\operatorname{Sim}(n=12)$ & 23,5 & 31,4 & 45,1 & 0,343 & 15,7 & 62,7 & 21,6 & 0,134 & 1,9 & 11,8 & 86,3 & 0,097 \\
\hline Não (n=51) & 8,3 & 25,0 & 66,7 & & 8,3 & 41,7 & 50,0 & & 16,7 & 8,3 & 75,0 & \\
\hline
\end{tabular}

\section{DISCUSSÃO}

Não existe consenso na literatura para diagnosticar o burnout. A constatação da síndrome num pequeno percentual da população estudada, devendo-se, ao menos em parte, ao fato de se adotar os critérios preconizados por Maslach, referidos por vários autores ${ }^{(1-2,7)}$, os quais são considerados mais rígidos porque enfatizam as interrelações entre as três dimensões do burnout. Em estudo ${ }^{(13)}$ realizado junto a equipe de enfermagem, em hospital da região Sul do Brasil, empregando critério semelhante, identificou-se a ausência da síndrome. Por sua vez, outros autores ${ }^{(19)}$ diagnosticam o burnout quando da presença isolada de um nível alto de exaustão emocional ou despersonalização, ou nível baixo em realização pessoal no trabalho. Segundo este critério, na pesquisa atual e naquela efetuada no Sul do País ${ }^{(13)}$, respectivamente, $68,3 \%$ dos enfermeiros e $35,7 \%$ dos trabalhadores de enfermagem estava com burnout, já que apresentou ao menos uma dimensão da síndrome em nível crítico. Esta definição minimiza a complexidade do processo sequencial que resulta no burnout.

Apesar da baixa frequência de burnout entre os enfermeiros avaliados, os altos níveis encontrados de exaustão emocional e despersonalização indicavam forte propensão para o desenvolvimento da síndrome. A proporção de enfermeiros com nível alto de exaustão emocional $(49,1 \%)$ e de despersonalização $(27,0 \%)$ observada na presente pesquisa foi consideravelmente maior do que a encontrada entre trabalhadores de enfermagem em hospital de Madrid: $11,7 \%$ de exaustão e $9,2 \%$ de despersonalização, com os enfermeiros apresentando os níveis maiores em ambas as dimensões(12), bem como em Tubarão (SC): $6 \%$ com alto nível de exaustão e $21,9 \%$ de despersonalização(13) . Os resultados em hospital de Londrina (PR) também mostram quantitativo menor de profissionais de enfermagem com alta exaustão emocional $(21,3 \%)$, sendo maior a presença de alta despersonalização (32,8\%)(15).

O encadeamento de eventos negativos do burnout começa com o cansaço e o desgaste físico e mental continuado que levam o profissional à exaustão emocional(1). Na tentativa de superar as condições adversas, a gradual e sutil tendência a negligenciar suas próprias necessidades, a negação crescente dos problemas e a repressão de conflitos, provocam emoções e atitudes negativas relacionadas ao trabalho. O burnout se revela quando a superposição de exaustão emocional e despersonalização conduzem ao sentimento de baixa realização laboral. Existem diferen- 
ças entre autores acerca da sequência de encadeamento dos eventos negativos e do significado das manifestações, mas os três componentes descritos são fundamentais no burnout ${ }^{(7)}$.

Já que a síndrome evolui de forma progressiva, com um caráter cumulativo, podendo ocorrer num período de tempo mais curto ou levar anos para se manifestar ${ }^{(1-3)}$, uma incursão às respostas aos itens do $\mathrm{MBI}$ retratou uma situação preocupante. A subescala exaustão emocional evidenciou que, praticamente todos os dias, quase duas quintas partes dos enfermeiros se sentiam sobrecarregados e esgotados com a rotina de trabalho e um quarto desses profissionais estavam no limite de suas possibilidades. Foram poucos aqueles que não referiram sobrecarga no trabalho e esgotamento. Estudos têm mostrado que a sobrecarga laboral representa uma fonte de estresse crônico entre enfermeiros, constituindo-se num dos principais preditores da exaustão emocional| ${ }^{(8,10,20)}$, dimensão do burnout que é considerada como etapa inicial e fator central da síndrome ${ }^{(6)}$. Os sentimentos de cansaço por trabalhar com pessoas, decepção e frustração, ainda que esporádicos, estavam presentes em grande parte da população estudada.

Na pesquisa atual, a realização das tarefas com muita rapidez e a percepção de que o salário recebido era incompatível com o esforço empregado na efetivação das tarefas, semelhante ao identificado em outras ${ }^{(3,6,7,21)}$ mostraram-se estatisticamente associados com altos níveis de exaustão emocional. O hiato entre salário e esforço leva à percepção de falta de retribuição à sua dedicação. Nessas circunstâncias, a exaustão remete, sobretudo, ao rompimento da reciprocidade entre os profissionais e a organização a qual estão vinculados, que dá origem ao sentimento de injustiça. As recompensas (ascensão funcional, salário, cuidados com o bem-estar) representam um elemento importante do suporte organizacional percebido. Pesquisas desenvolvidas em distintos contextos de trabalho( ${ }^{(2)}$, inclusive no Brasil(5-6), evidenciam a relação direta entre o esgotamento crônico e a percepção de suporte organizacional insuficiente.

O desafio entre o que há para ser feito e o tempo disponível para fazê-lo deixa o trabalhador submetido à enorme tensão, particularmente, diante da responsabilidade de efetuar um trabalho qualificado, aumentando o cansaço, o desgaste e o esgotamento crônico. Todavia, a exaustão não foi o único evento negativo resultante da pressão do tempo, os sentimentos e atitudes negativas no trabalho que caracterizam a despersonalização também se fizeram presentes de modo significativamente maior entre os enfermeiros que requentemente/sempre precisavam agir com rapidez na efetuação de suas tarefas. O caráter recursivo da relação entre a pressão do tempo e o burnout compromete cada vez mais a saúde do trabalhador ${ }^{(21)}$.

A tendência para apresentar níveis altos de exaustão emocional identificada entre as mulheres e aqueles com menor tempo de profissão, estes últimos também tiveram níveis significativamente mais altos de despersonalização, guarda consonância com os resultados de pesquisas nacionais $^{(10)}$ e internacionais ${ }^{(8,11,20)}$. A maior concentração de esgotamento e de sentimentos e atitudes negativas relacionadas ao trabalho entre aqueles com menor tempo, associa-se com expectativas não concretizadas e com dificuldade para vislumbrar maiores possibilidades de meIhoria nas condições laborais ${ }^{(10,22)}$. Aqueles com mais tempo de profissão sentem o cansaço e o desgaste, mas para manter o otimismo continuam esperando uma solução, talvez porque estejam mais complacentes ou extraiam aspectos positivos de experiências negativas. Um estudo ${ }^{(10)}$ lembra que aqueles mais antigos na profissão que estavam insatisfeitos com o trabalho e tiveram oportunidade de mudança, já podem ter seguido outros caminhos.

A nítida predominância do gênero feminino, nesta pesquisa, está de acordo com o fato de que o exercício profissional da enfermagem é mais frequente entre as mulheres ${ }^{(8,13,15,20)}$. Vários argumentos têm sido utilizados para apoiar a conclusão de que as mulheres são mais vulneráveis ao burnout do que os homens. Primeiro, os papéis atribuídos aos gêneros no processo de socialização, com as mulheres estando mais propensas a envolver-se emocionalmente com os problemas das pessoas a quem prestam serviço. Segundo, as mulheres têm maior probabilidade de optarem por profissões que envolvem contato mais direto com as pessoas. Terceiro, estão submetidas a uma dupla jornada de trabalho (cuidados do lar e desempenho profissional). Quarto, as mulheres usam como mecanismos de defesa básicos a negação e a repressão: negam ou não querem perceber as suas frustrações, seu mal-estar e exaustão, sempre achando que podem ultrapassar os seus próprios limites em cada um dos múltiplos papéis que desempenham na vida ${ }^{(10,20)}$.

Um estudo ${ }^{(20)}$ com integrantes da equipe de enfermagem, na Espanha, conclui pela existência de padrões diferenciados para homens (níveis mais altos de despersonalização e a realização profissional não é um preditor significativo da despersonalização) e mulheres (a exaustão emocional não prediz o absenteísmo). Porém, alerta que o forte predomínio de mulheres nesta categoria profissional pode encobrir a influência do gênero sobre o burnout. No Brasil, na região Sul, pesquisa com trabalhadores de enfermagem encontra valores mais elevados na subescala de despersonalização para o gênero masculino e níveis semelhantes de exaustão emocional em homens e mulheres $^{(10)}$. Diferentes autores consideram que o estresse e o burnout em mulheres se revestem de características especiais que precisam ser compreendidas e levadas em conta pelos programas de prevenção(10,20).

Com relação à despersonalização, quase todos os dias uma pequena parcela dos enfermeiros, cuja importância não deveria ser minimizada devido às repercussões negativas sobre a saúde e a qualidade do trabalho, percebeu a 
falta de reciprocidade com os pacientes e recorreu à dureza no tratamento e ao distanciamento emocional excessivo. Esta percepção e atitudes também ocorreram, algumas vezes por ano, em aproximadamente metade desses profissionais. Convém atentar-se que pode ser que haja interferência da desejabilidade social nas respostas dadas aos itens dessa dimensão, uma vez que os mesmos desafiam a imagem profissional do trabalhador de serviços humanos $^{(8)}$. Ademais, os resultados dizem respeito a uma população com nítida predominância do gênero feminino que, considerando os modelos de socialização ainda hegemônicos, é condicionado para o cuidado ${ }^{(8,10,20)}$.

A falta de reciprocidade, que restringe a gratidão e o respeito dos beneficiários dos serviços, origina o sentimento de ser injustiçado, podendo comprometer o vínculo profissional-usuário. Pesquisas mostram correlação positiva significativa entre a percepção de falta de reciprocidade com os pacientes e as duas dimensões do burnout, exaustão emocional e despersonalização(7-8). Por sua vez, o distanciamento emocional contraproducente, no qual o profissional recorre às estratégias de escape e trata o usuário com indiferença, produzido ao longo do processo de despersonalização, é uma forma de enfrentamento do esgotamento emocional que evidencia a necessidade urgente de uma ação que comprometa a instituição com a saúde e a qualidade de vida no trabalho. A busca de soluções individuais para problemas coletivos facilita a aparição do burnout $^{(16-17)}$. Ressaltou-se, como aspecto positivo, a importância que os enfermeiros conferiam às pessoas atendidas.

Encontraram-se níveis altos de realização pessoal no trabalho $(84,1 \%)$, bastante superiores aos $35,0 \%$, bem como aos $50,3 \%$ e $37,7 \%$ mencionados, respectivamente, por pesquisadores $^{(12-13,15)}$. A grande maioria desses profissionais, corriqueiramente, atendia às pessoas com facilidade e reconhecia a importância do trabalho que realizavam, não estando imbuídos de sentimentos de inadequação e fracasso. A percepção da utilidade do próprio trabalho tem valor inegável para a auto-estima do trabalhador ${ }^{(10,21)}$. Contudo, vislumbrava-se alguma dificuldade para manejar os problemas emocionais com calma e para sentir-se vigoroso no trabalho. A baixa realização profissional, à parte o lugar que ocupa na sequência de aparecimento das manifestações associadas ao burnout, é um elemento-chave dessa síndrome, motivando um menor envolvimento no trabalho e podendo provocar a vontade de desistir ${ }^{(7)}$.

Aproximadamente uma quarta parte desses profissionais superpunha alta exaustão emocional e despersonalização, o que permite sugerir que estava em quase-burnout, com a energia inicial se transformando em fadiga crônica, sendo crescente o sentimento de frustração ${ }^{(2,18)}$. A alta realização pessoal no trabalho, certamente, constituía-se como um elemento fundamental para a manutenção deste estágio de transição em direção à síndrome na população avaliada. Mesmo entre os profissionais que se percebem como levados ao limite de suas resistências, ainda podem ser incipiente a insatisfação ${ }^{(21)}$. Pesquisas realizadas em distintos países constatam a satisfação com o trabalho não obstante o elevado nível de estresse ${ }^{(4)}$. Em estudo efetuado numa organização hospitalar brasileira identifica-se a satisfação como um fator de proteção contra o burnout ${ }^{(16)}$.

Dimensão fundamental para concretizar a passagem do quase-burnout para o burnout, a baixa realização pessoal no trabalho apresentou maior tendência para ser identificada entre os profissionais que acumulavam funções diferentes e que não acreditavam ser possível obter ascensão profissional. A superposição de atribuições conduz à percepção de que os recursos de que se dispõe são menores do que os necessários para realizar as tarefas previstas. Diversos autores relacionam a síndrome com acúmulo de tarefas pelo mesmo indivíduo, impossibilidade de ascender na carreira e obter reconhecimento de seu trabalho, reiterando a importância da percepção de suporte organizacional insuficiente sobre a saúde no trabalho ${ }^{(3,5-6,10)}$. Todos esses aspectos, isolados ou potencializados pela interação, provocam a sensação de desequilíbrio crônico em que o trabalho exige muito mais do que a pessoa pode dar e proporciona menos do que ela precisa.

\section{CONCLUSÃO}

A frequência de burnout era baixa na população estudada, mas os resultados despertam preocupação, particularmente, devido ao caráter sorrateiro da síndrome, uma vez que algum dos seus sentimentos e atitudes constituintes pode estar presente de modo intermitente, avançando com o tempo. A sobrecarga de trabalho, o esgotamento e o recurso às estratégias centradas na emoção, entre outros aspectos, consubstanciados nos níveis altos e médios de exaustão emocional e despersonalização que foram identificados, evidenciam o comprometimento da qualidade de vida no trabalho. A superposição de exaustão e despersonalização permite, inclusive, falar em situação de quase-burnout, num contexto em que o suporte organizacional foi percebido como insuficiente, sobretudo, pelos enfermeiros com menos de cinco anos de atividade profissional.

Não se pode minimizar a ambiguidade das vivências no mundo do trabalho, pois mesmo sob condições desfavoráveis o trabalho pode produzir algum grau de satisfação. Essa complexidade das interações que podem ser, ao mesmo tempo, fonte de prazer e de sofrimento, torna uma maior diversificação de estratégias para lidar com a coexistência de desgaste e satisfação num elemento fundamental para a promoção da qualidade de vida no trabalho. Logo, o enfrentamento do burnout não pode descartar nem processos individuais, nem processos organizacionais de meIhor suporte ao trabalho das equipes e à saúde de seus integrantes. É provável que por esse caminho se possam encontrar formas alternativas de tratar o balanceamento entre diferenciações e integrações, o qual é considerado como um problema central para os coletivos organizados. 
Convém ficar atento para o fato de que a busca de encontrar soluções pessoais para os problemas do trabalho, favorece menos à própria saúde e ao trabalho executado. Os profissionais podem sentir-se mais tranquilos, adaptando as suas expectativas com relação ao trabalho. Todavia, em longo prazo, a persistência das condições laborais

\section{REFERÊNCIAS}

1. Gil-Monte P, Peiró JM. Perspectivas teóricas y modelos interpretativos para el estudio del síndrome de quemarse por el trabajo. An Psicol. 1999;15(20):261-8.

2. Ruiz CO, Rios FL. El burnout o síndrome de estar quemado en los profesionales sanitarios: revisión y perspectivas. Int J Health Psychol. 2004;4(1):137-60.

3. Trigo TR, Teng CT, Hallak JED. Síndrome de burnout ou estafa profissional e os transtornos psiquiátricos. Rev Psiquiatr Clín. 2007;34(5):223-33.

4. Hall E. Nurse burnout in a high stress health care environment: prognosis better than expected? [Internet]. [cited 2010 June 7]. Available from: http://eprints.otago.ac.nz/278/1/ Hall_working_paper2.pdf

5. Oliveira PR, Tristão RM, Neiva ER. Burnout e suporte organizacional em profissionais de UTI Neonatal. Educ Profis Ciênc Tecnol. 2006;1(1):27-37.

6. Tamayo MR, Tróccoli BT. Exaustão emocional: relações com a percepção de suporte organizacional e com as estratégias de coping no trabalho. Est Psicol. 2002;7(1):37-46.

7. Tamayo M, Tróccoli BT. Burnout no trabalho. In: Mendes AM, Borges LO, Ferreira MC, organizadores. Trabalho em transição, saúde em risco. Brasília: Ed. UNB; 2002. p. 45-63.

8. Gil-Monte PR. El síndrome de quemarse por el trabajo (síndrome de burnout) en profesionales de enfermería. Rev Eletr InterAção Psy [Internet]. 2003 [citado 2010 nov. 13];1(1):1933. Disponível em: http://www.bvsde.paho.org/bvsacd/cd49/ artigo3.pdf

9. Murofuse NT, Abranches SS, Napoleão AA. Reflexões sobre estresse e burnout e a relação com a enfermagem. Rev Latino Am Enferm. 2005;13(2):255-61.

10. Benevides-Pereira AMT. As atividades de enfermagem em hospital: um fator de vulnerabilidade ao burnout. In: Benevides-Pereira AMT, organizador. Burnout: quando o trabalho ameaça o bem-estar do trabalhador. São Paulo: Casa do Psicólogo; 2002. p. 133-55.

11. Nordang K, Hall-Lord ML, Farup PG. Burnoutein health-care professionals during reorganizations and downsizing: a cohort study in nurses. BMC Nurs. 2010;9:8. geradoras do estresse, potencializa a exaustão emocional, a despersonalização e a baixa realização no trabalho. Certamente, o desafio da promoção da saúde no trabalho e da prevenção do burnout, torna-se ainda maior na medida em que é exigido um diálogo permanente entre o planejamento, a execução e a gestão.
12. Albaladejo R, Villanueva R, Ortega $P$, Astasio $P$, Calle $M E$, Dominguez V. Síndrome del burnout en el personal de enfermeria en un hospital de Madrid. Rev Española Salud Pública. 2004;78(4):506-16.

13. Moreira DS, Magnago R, Sakae TM, Magajewski FRL. Prevalência da síndrome de burnout em trabalhadores de enfermagem de um hospital de grande porte da Região Sul do Brasil. Cad Saúde Pública. 2009;25(7):1559-68.

14. Grau A, Suñer R, García MM. Desgaste profesional en el personal sanitario y su relación con los factores personales y ambientales. Gaceta San. 2005;19(6):463-70.

15. Jodas DA, Haddad MCL. Síndrome de burnout em trabalhadores de enfermagem de um pronto socorro de hospital universitário. Acta Paul Enferm. 2009;22(2):192-7.

16. Rosa C, Carlotto MS. Síndrome de burnout e satisfação no trabalho em profissionais de uma instituição hospitalar. Rev SBPH. 2005;8(2):1-15.

17. Lemaire JB, Wallace JE. Not all coping strategies are created equal: a mixed methods study exploring physicians' self reported coping strategies. BMC Health Serv Res. 2010;10(2):208.

18. Lautert L. O desgaste profissional do enfermeiro [tese doutorado]. Salamanca: Faculdade de Psicologia, Universidade Pontifícia de Salamanca; 1995.

19. Grunfeld E, Whelan TJ, Zitzelsberger L, Willan AR, Montesanto $B$, Evans WK. Cancer care workers in Ontario: prevalence of burnout, job stress and job satisfaction. CMAJ. 2000; 163(1):166-9.

20. Gil-Monte PR. Influencia del género sobre el proceso de desarrollo del síndrome de quemarse por el trabajo (burnout) en profesionales de enfermería. Psicol Estudo. 2002;7(1): 3-10.

21. Soratto L, Pinto RM. Burnout e carga mental no trabalho. In: Codo W, organizador. Educação: carinho e trabalho. 2a ed. Petrópolis: Vozes; 2000. p. 282-92.

22. Trindade LL, Lautert L. Síndrome de burnout entre os trabaIhadores da Estratégia de Saúde da Família. Rev Esc Enferm USP. 2010;44(2):274-9. 